\title{
Nutritional status of preschool children attending kindergartens in Kosovo
}

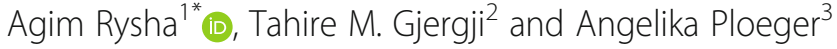

\begin{abstract}
Background: There is very limited data on malnutrition of preschool children in Kosovo. The main objective of the study is to provide a nutritional status profile of preschool children attending kindergartens in Kosovo.

Methods: Cross-sectional study of children aged 12-59 months ( $n=352$ children) and children aged 60-83 months $(n=134)$ enrolled in public and private kindergartens of Kosovo. Anthropometric measurements used for this study are weight and height of the preschoolers (12-83 months). A measuring board was used for measuring the length/ height of children younger than 2 years, while digital weight and height scale Seca 763 was used for measuring of preschool children taller than 110 and Seca 213 was used for measuring the height for children who were shorter than $110 \mathrm{~cm}$. Statistical analyses of underweight and overweight trends across sex and age groups as well as between children from public and private kindergartens were carried out. Qualitative variables were tested with a chi-square test. The differences between groups were assessed with a Student $t$ test for normally distributed variables and a Mann-Whitney test for abnormally distributed numerical variables.
\end{abstract}

Results: The mean z-scores for weight-for-age, height-for-age, weight-for-height, and BMI-for-age largely fell within 0.0 and 1.0. The percentage of stunted children is $3 \%$, whereas child wasting is $1.9 \%$. The overall percentage of obese children is 2.3\%; furthermore, $8.9 \%$ are overweight and $27.3 \%$ have a possible risk of being overweight.

Conclusions: The incidence of children underweight is slightly decreasing. The prevalence of overweight and obese children in sample chosen is evident.

Keywords: Kosovo, Preschool children, Child underweight, Child overweight

\section{Background}

Countries throughout the world are at various stages of nutritional transition and, increasingly, they are documenting that food insecurity and under-nutrition exist side by side with problems of over-nutrition, obesity and chronic diseases [1]. Different diseases of adults are considered to have a close relationship with malnutrition and incorrect or improper nutrition in childhood. The association between childhood diet and being underweight or overweight as children or even as adults has been shown in numerous studies [2-4]. Global evidence indicates increase of obesity, diabetes, cardiovascular diseases, and other chronic non-communicable diseases, especially in developing and transitional countries. This evidence also indicates that disease processes begin early

\footnotetext{
* Correspondence: agim.rysha@unhz.eu

'Department of Food Technology, Faculty of Agribusiness, University of Pejë, Rr. "UÇK-së", 30000 Pejë, Kosovo

Full list of author information is available at the end of the article
}

in life, and it is expected that the epidemic will continue to increase due to a lifetime of exposure to poor diet and the influence of different factors [5, 6].

Proper nutrition in childhood is considered to play a crucial role in the physical, mental, and emotional development of children through to their later adult age. Children are therefore considered the priority population for intervention strategies [7]. Nutritional assessment in children is needed to determine their nutritional status and problems in their food regimes and if identified, to treat such problems in order to prevent them from becoming larger and threatening to children's health. Therefore, many studies are taking place, for example, in preschool institutions and kindergartens.

Anthropometry is a practical and immediately applicable technique for assessing children's development patterns. Anthropometric indicators can be used as a screening device to identify individuals at risk of 
under-nutrition or over-nutrition, followed by a more elaborate investigation using other techniques [8]. Complementary to this assessment the BMI (body mass index) $\mathrm{z}$-scores has been recommended as the most appropriate single indicator of overweight status and obesity in children and adolescents outside of research settings [9-11].

Kosovo, as the youngest country in accession discussion with the EU, is among a few countries without any National Nutrition Strategy or Nutrition Education Program. According to the 2009 Kosovo education statistics, the number of preschool establishments (kindergartens) was 40 with a total of 5091 children enrolled, divided into two groups (a) toddlers aged 1-3 years and (b) preschoolers aged 4-6 years [12]. The percentage of preschool-aged children attending kindergartens in Kosovo is very low (less than $10 \%$ ). There is a high demand by families to send their children to kindergartens, but a lack of kindergartens and budget limitations prevent many children from attending such preschool institutions.

Based on literature exploration, the statistics and investigation on nutrition and health characteristics of the country seem to be scarce, and there is very limited data on malnutrition and overweight preschool children in Kosovo. According to the survey conducted by UNICEF in July 1999 [13], the acute malnutrition was detected in $3.1 \%$ of the children from $0-5$ years (including $1 \%$ severe) and chronic malnutrition was present in $10.7 \%$ of the children (including 3\% severe). In 2001, the United Nations Children's Fund [14], in collaboration with the Institute for Public Health of Kosovo, promoted a survey on the health and nutrition of women and children. Low height-for-age was found in $10 \%$ of the children aged 6-59 months while the prevalence of low weight-for-height was $4 \%$.

The main objective of this study is to provide preliminary data on nutritional status in preschool children attending public and private kindergartens in Kosovo. Since Kosovo did not yet develop its own national standards for nutritional guidelines and nutritional assessment, the growth of preschool children was examined to determine whether and how the anthropometric indicators of selected samples differ from actual WHO standards and references, which are mainly used for the screening, surveillance, and monitoring of preschool children. It is expected that the growth of preschool children in Kosovo is not in line with international standards and references for weight-for-age, height-for-age, weight-for-height, and BMI-for-age.

\section{Methods}

This cross-sectional study covered four public and one private kindergarten, randomly selected from different regions of Kosovo (Prishtinë; Ferizaj; Kamenicë and Obiliq). The study population included 486 children and the distribution of the study subjects by age and sex is presented in Table 1. Kindergartens in Kosovo are frequented by children of families with different economic, social, and cultural levels.

All registered children from the selected kindergartens were eligible to participate in the anthropometric assessment. The inclusion criteria for the recruited subjects were (a) children registered and attending the selected kindergarten, and (b) children between 12 and 83 months of age.

In order to conduct a study involving preschool children, institutional consent for access to the kindergartens as well as parental consent was needed. The request for access to preschool settings was addressed to the Ministry of Education, Science and Technology of Kosovo. The Ministry has issued a consent letter, inviting Municipal Education Directors as well as the Kindergarten Directors to support this study. The concept and the objective of the study were explained to the parents and teachers (nursery governess) through group meetings as well as through distributing of an information letter to each parent personally. All parents agreed to have their children participate. An information poster about the start and time frame of the study was placed on the entrance door of each kindergarten prior to the beginning of the research. Anthropometric measurements used for this study are weight and height of the preschoolers (12-83 months) according to the techniques which were suggested by the WHO [15]. A measuring board was used for measuring the length/height of children younger than 2 years. Digital weight and height scale Seca 763 was used for measuring the weight of all assessed children and the height of preschool children taller than $110 \mathrm{~cm}$. The measuring range of the equipment is between $110-200 \mathrm{~cm}$ with the graduation weight of $50 \mathrm{~g}$ and graduation length of $1 \mathrm{~mm}$. With Seca 763, both weight and height can be done in one step, calculating the BMI of the patient in an automatic way.

Table 1 Distribution of study subjects by age and sex

\begin{tabular}{|c|c|c|c|c|c|}
\hline \multirow{3}{*}{$\begin{array}{l}\text { Age groups } \\
\text { (months) }\end{array}$} & \multicolumn{4}{|c|}{ Gender } & \multirow{3}{*}{$\begin{array}{l}\text { Total } \\
\text { N }\end{array}$} \\
\hline & \multicolumn{2}{|c|}{ Female } & \multicolumn{2}{|c|}{ Male } & \\
\hline & $\bar{N}$ & $\%$ & $\bar{N}$ & $\%$ & \\
\hline $12-23$ & 17 & 7.7 & 27 & 10.2 & 44 \\
\hline 24-35 & 35 & 15.8 & 35 & 13.3 & 70 \\
\hline $36-47$ & 66 & 29.7 & 58 & 22.0 & 124 \\
\hline $48-59$ & 43 & 19.4 & 71 & 26.9 & 114 \\
\hline $60-71$ & 51 & 23.0 & 50 & 18.9 & 101 \\
\hline $72-83$ & 10 & 4.5 & 23 & 8.7 & 33 \\
\hline Total & 222 & 100.0 & 264 & 100.0 & 486 \\
\hline
\end{tabular}


Indicated values provide information on the general nutritional condition of the user on the basis of recognized WHO standards. Height measuring instrument Seca 213 with graduation length of $1 \mathrm{~mm}$ was used for measuring the height of children who were shorter than $110 \mathrm{~cm}$. This stadiometer is reliable and can be used anywhere because the large floor plate provides the necessary stability, and it is easy to read the results while measuring, thus guaranteeing precise results. The length and height measurement in this study is taken to the nearest $0.5 \mathrm{~cm}$ (5 $\mathrm{mm}$ ). The body weight was measured with the child in underwear or in light clothing, without shoes. The weight measurement in this study is taken to the nearest $0.1 \mathrm{~kg}$. Measurements on weight and height were taken from children aged 12-83 months directly in five kindergartens. The data was recorded by a principal investigator who was supported by trained nurses in conducting the measurement of a child's length/height and weight. The principal investigator stayed in the kindergartens for the duration of survey. Results of the measurements of weight and height of preschool children in Kosovo have been compared with the growth charts from the World Health Organization. The 2006 WHO Child Growth Standards were applied for the children aged 1259 months and the Growth Reference 2007 for children aged 60-83 months. Anthropometric indices were constructed by comparing the study data (12-83 months aged children) with those of comparable individuals in the WHO reference data. Z-scores (standard deviation score) were used for expressing these comparisons. Anthropometric indicators WAZ (weight-for-age z-scores), HAZ (length-or height-for-age z-scores), WHZ (weight-for-height z-scores), and BAZ (BMI-for-age z-scores) were used for children of the age group 12-59 months, while weight-for-age ( $z$ scores), height-for-age (z-scores), and BMI-for-age ( $\mathrm{z}$ scores) parameters were used for the children aged 6083 months. The cutoffs recommended by the WHO, which were used in the study for screening of under-nutrition and over-nutrition are presented in Table 2.

Anthropometric software provided by the WHO was used for conversion of data into anthropometric indices according to both, standards and WHO references [16, 17]. Statistical analyses were carried out using statistical package SPSS version 17.0. The mean values of body mass and stature across sex and age groups as well as means and SD of anthropometric indicators (HAZ, WHZ, and BAZ) between public and private kindergartens were compared. Qualitative variables were tested with a chi-square test. The differences between groups were assessed with a Student $t$ test for normally distributed variables, and a Mann-Whitney test was used for not normally distributed numerical variables. The level of significance adopted for the statistical test was 5\%.

\section{Results}

This investigation, which was conducted in preschool settings in Kosovo, sought to construct a profile of the nutritional status of preschool children attending kindergartens in Kosovo.

Results of anthropometric indicators presented in Table 3 show that mean $\mathrm{z}$-scores for weight-for-age, height-for-age, weight-for-height, and BMI-for-age largely fell within 0.0 and 1.0. For weight-for-age, which reflects the proportion of body mass to chronological age, the categories having the lowest mean z-scores were boys aged $72-<84$ months $(-0.1 \pm 1.4)$, while the categories having the highest mean $\mathrm{z}$-scores were boys aged $12-<24$ months $(0.8 \pm 1.2)$ and also girls aged $12-<24$ months. Statistical tests did not show significant differences $(p>0.05)$ in WAZ between girls and boys.

For height-for-age, which reflects achieved linear growth, the categories having the lowest mean z-scores were again boys aged $72-<84$ months $(-0.2 \pm 1.2)$, while the categories having the highest mean z-scores were

Table 2 The WHO cutoffs for screening of under-nutrition and over-nutrition

\begin{tabular}{|c|c|c|}
\hline Parameter & $\begin{array}{l}2006 \\
\text { WHO standards }\end{array}$ & $\begin{array}{l}2007 \\
\text { WHO reference }\end{array}$ \\
\hline Underweight (weight-for-age) & $<-2$ z-scores & $<-2$ z-scores \\
\hline Severe underweight (weight-for-age) & $<-3$ z-scores & $<-3$ z-scores \\
\hline Stunting (length-height-for-age) & $<-2$ z-scores & $<-2$ z-scores \\
\hline Severe stunting (length-height-for-age) & $<-3$ z-scores & $<-3$ z-scores \\
\hline Wasting (weight-for-length-BMI-for-age ${ }^{\mathrm{a}}$ ) & $<-2$ z-scores & $<-2$ z-scores \\
\hline Severe wasting (weight-for-height) & $<-3$ z-scores & $<-3$ z-scores \\
\hline Risk of overweight (weight-for-length/BMl-for-age ${ }^{a}$ ) & $>+1$ z-scores & $\mathrm{n} / \mathrm{a}$ \\
\hline Overweight (weight-for-length/BMI-for-age ${ }^{\mathrm{a}}$ ) & $>+2$ z-scores & $>+1$ z-score \\
\hline Obese (weight-for-length/BMI-for-age ${ }^{\mathrm{a}}$ ) & $>+3$ z-scores & $>+2$ z-score \\
\hline Severe obesity (BMI-for-age) & $\mathrm{n} / \mathrm{a}$ & $>+3$ z-scores \\
\hline
\end{tabular}

n/a not applicable

a'Weight-for-length from birth to 2 years; BMI-for-age > 2 years 
Table 3 Mean and standard deviations of WAZ, HAZ, WHZ, and BMI scores by age and sex

\begin{tabular}{|c|c|c|c|c|c|c|c|}
\hline \multirow{2}{*}{$\begin{array}{l}\text { Age groups } \\
\text { (months) }\end{array}$} & \multicolumn{2}{|c|}{ Female } & \multicolumn{2}{|l|}{ Male } & \multicolumn{2}{|l|}{ Total } & \multirow[t]{2}{*}{$p$ value } \\
\hline & Mean & SD & Mean & SD & Mean & SD & \\
\hline & \multicolumn{6}{|c|}{ Weight for age (z-scores) } & \\
\hline $12-23$ & 0.8 & 0.9 & 0.8 & 1.2 & 0.8 & 1.1 & 0.979 \\
\hline 24-35 & 0.7 & 1.2 & 0.6 & 1 & 0.7 & 1.1 & 0.700 \\
\hline $36-47$ & 0.2 & 1 & 0.4 & 1 & 0.3 & 1 & 0.200 \\
\hline $48-59$ & 0.2 & 0.9 & 0.5 & 1.1 & 0.4 & 1.1 & 0.278 \\
\hline 60-71 & 0.4 & 1.1 & 0.3 & 1.1 & 0.3 & 1.1 & 0.572 \\
\hline \multirow[t]{2}{*}{$72-83$} & 0.6 & 0.9 & -0.1 & 1.4 & 0.1 & 1.3 & 0.196 \\
\hline & \multicolumn{6}{|c|}{ Height for age (z-scores) } & \\
\hline $12-23$ & 0.3 & 1.1 & 1.1 & 2.3 & 0.8 & 2 & 0.664 \\
\hline 24-35 & 0.3 & 1.5 & -0.1 & 1 & 0.1 & 1.3 & 0.191 \\
\hline $36-47$ & 0.1 & 1.1 & 0.2 & 1 & 0.1 & 1 & 0.524 \\
\hline $48-59$ & 0 & 0.9 & 0.2 & 1 & 0.1 & 1 & 0.418 \\
\hline $60-71$ & 0.2 & 1.3 & 0.1 & 1 & 0.1 & 1.1 & 0.640 \\
\hline \multirow[t]{2}{*}{$72-83$} & 0.4 & 1.1 & -0.2 & 1.2 & 0 & 1.2 & 0.179 \\
\hline & \multicolumn{6}{|c|}{ Weight for height (z-scores) } & \\
\hline $12-23$ & 0.8 & 0.7 & 0.4 & 1.1 & 0.6 & 1 & 0.207 \\
\hline 24-35 & 0.7 & 1.1 & 0.9 & 1.1 & 0.8 & 1.1 & 0.458 \\
\hline $36-47$ & 0.2 & 1.1 & 0.4 & 1 & 0.3 & 1.1 & 0.233 \\
\hline $48-59$ & 0.3 & 0.9 & 0.5 & 1.1 & 0.4 & 1 & 0.634 \\
\hline \multirow[t]{2}{*}{ 60-71 } & 0.7 & 1.7 & 0.6 & 0.7 & 0.7 & 1.3 & 0.904 \\
\hline & \multicolumn{4}{|c|}{ BMI for age (z-scores) } & & & \\
\hline $12-23$ & 0.9 & 0.6 & 0.3 & 1.3 & 0.5 & 1.1 & 0.123 \\
\hline 24-35 & 0.8 & 1.2 & 0.9 & 1.1 & 0.8 & 1.2 & 0.520 \\
\hline $36-47$ & 0.2 & 1.2 & 0.4 & 1 & 0.3 & 1.1 & 0.266 \\
\hline $48-59$ & 0.3 & 0.9 & 0.5 & 1.1 & 0.5 & 1 & 0.524 \\
\hline $60-71$ & 0.4 & 1 & 0.3 & 1.1 & 0.4 & 1 & 0.663 \\
\hline $72-83$ & 0.5 & 0.7 & 0.1 & 1.4 & 0.2 & 1.2 & 0.427 \\
\hline
\end{tabular}

boys aged $12-<24$ months $(1.1 \pm 2.3)$. No significant differences $(p>0.05)$ were noted in HAZ between girls and boys. For BMI-for-age as a recommended method for screening of overweight and underweight children, the categories having the highest mean $\mathrm{z}$-scores were girls aged $12-<24$ months $(0.9 \pm 1.2)$ and also boys aged $24-<35$ months. Gender differences were statistically tested also for WHZ and BMI, and no significant differences $(p>0.05)$ were noted between boys and girls.

Results of the weight-for-length/height and BMI-forage growth indicators are presented in Table 4. Weightfor-length/height growth indicator showed that $2.9 \%$ of 24-<36-month-old children were less than -2 z-scores, thus suffering from moderate acute malnutrition. The $-2 \mathrm{z}$-score values were observed also in two other groups: $2.4 \%$ in the age group of $24-<36$-month-old children and $2.3 \%$ in the group of $12-<24$-month-old children. It is observed that $2.3 \%$ of $12-<24$-month-old children and $0.8 \%$ of $36-<48$-month-old children are less than -3 z-scores suffering from severe acute malnutrition. In terms of gender, the highest prevalence of moderate acute malnutrition was observed in boys of the 12-<24-month-old group (3.7\%) and in girls of 24$<36$-month-old group. On the other side, the severe acute malnutrition was identified in boys of $12-<24$ month-old group (3.7\%) and in girls $36-<48$ months old.

BMI-for-age is used for screening for the risk of being overweight and for obesity in children aged 2483 months. The percentage of obese children is $2.3 \%$; furthermore, $8.9 \%$ are screened as overweight and $27.3 \%$ have a possible risk of being overweight. It is observed that $2.7 \%$ of boys and $1.4 \%$ of girls of the age group $24-$ 83 months are obese, $10.9 \%$ of boys and $5.9 \%$ of girls were overweight, and $29.1 \%$ of boys and $25.2 \%$ of girls are at risk of being overweight. Distribution of BMI-forage z-scores of children attending the kindergartens of Kosovo compared to the standard distribution of the World Health Organization is presented in Fig. 1.

\section{Discussion}

This study showed that the percentage of underweight children among the 486 assessed children attending preschool institutions (12-83 months) is $0.7 \%$, while $0.5 \%$ of the children are severely underweight. This percentage is lower than the average percentage from the study conducted in 2001 by the UNICEF [14], where the prevalence of underweight was $4 \%$. The percentage of stunted children attending five kindergartens in Kosovo is $3 \%$, and $0.7 \%$ are severely stunted. This measure of $3 \%$ is lower than the percentage from the study conducted in 2001 by the UNICEF, in which low height-for-age was found in $10 \%$ of the children aged 6-59 months. The weight-for-length/height shows that $1.9 \%$ of children (12-59 months) are less than -2 z-scores, thus suffering from moderate acute malnutrition or wasting and $0.8 \%$ of children are less than $-3 \mathrm{z}$-scores suffering from severe acute malnutrition. This percentage is much lower than results from the UNICEF survey of July 1999 [13], in which the acute malnutrition was detected in $3.1 \%$ of the children from 0 to 5 years (including $1 \%$ severe) and chronic malnutrition was present in $10.7 \%$ of the children (including 3\% severe).

Analyzing weight-for-age, length-height-for-age, and weight-for-length/height indicators, a reduction in underweight, stunting, and wasting of preschool-aged children from the year 1999 or 2001 could be seen in comparison to the time of this research. These results, which show a reduction in underweight when compared with results of research conducted by the UNICEF, may be not only due to improvement of living conditions in 


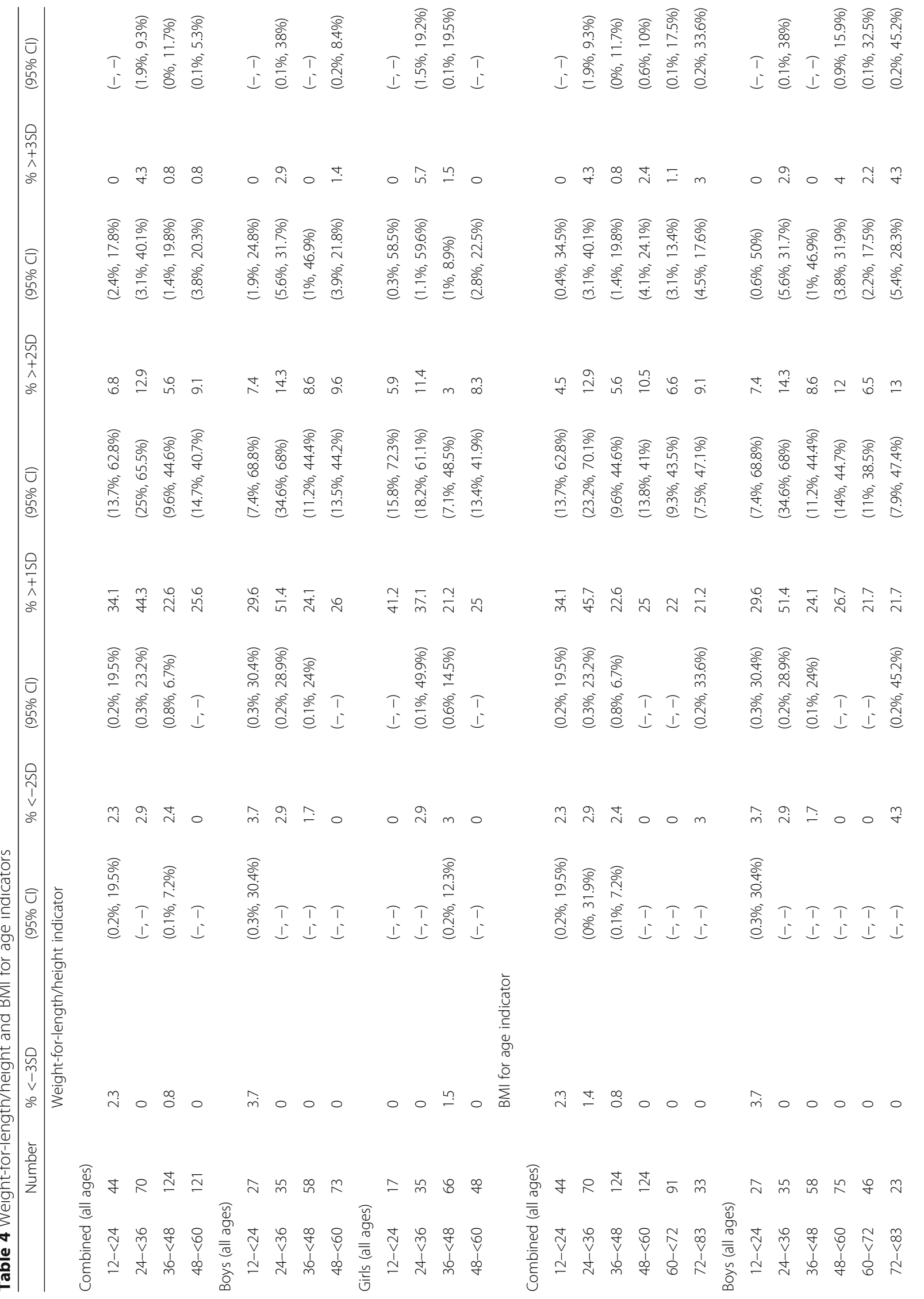




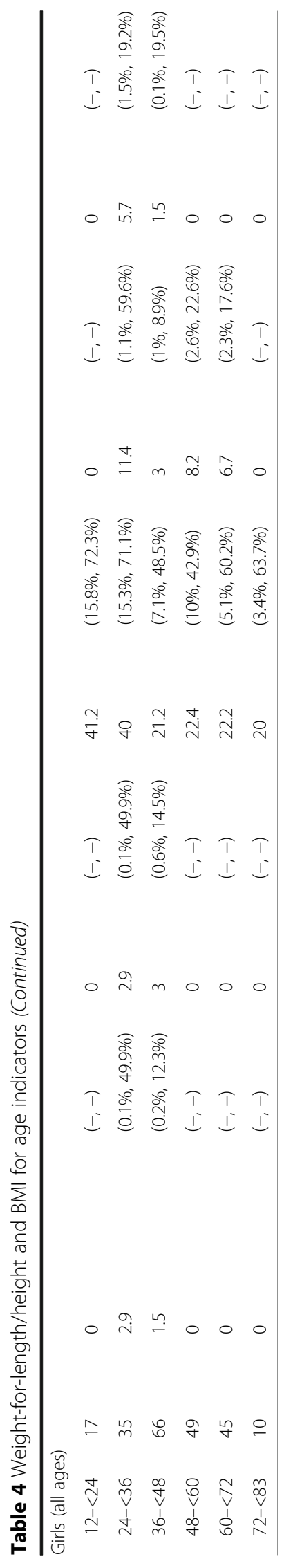



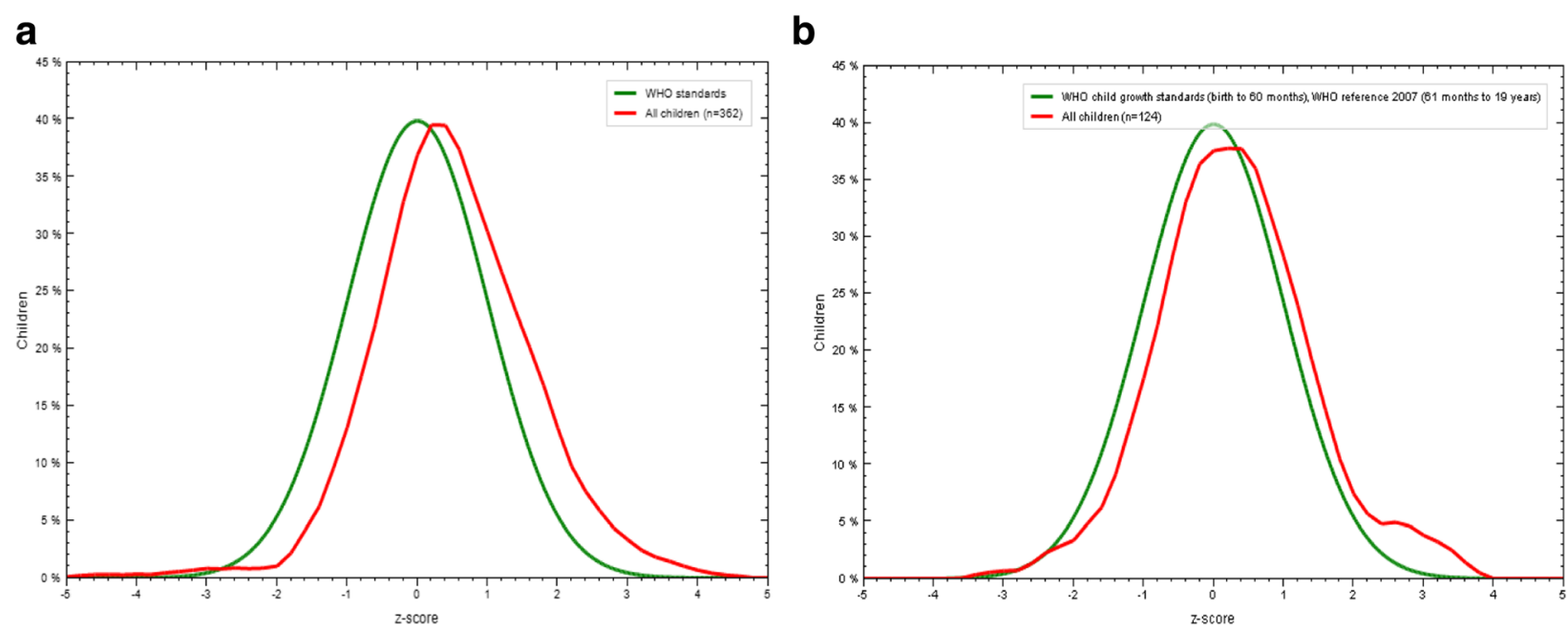

Fig. 1 Distribution of BMI for age z-scores of Kosovo preschool children compared with the WHO standard distribution (a) children 12-59 months (b) children 60-83 months

Kosovo after the war but also due to differences in sample characteristics of the present and previous studies.

\section{Conclusion}

The results of BMI-for-age, which is used for screening of overweight and obesity in 24-83-month-aged children, showed that the prevalence of being overweight in children is evident. This investigation presents that the prevalence of being overweight in assessed children is a less firm; thus, there is a need for prevention and control programs. The obtained results from this study are in line with other international studies showing that children being overweight, and childhood obesity are increasing in less developed countries as well as in transitional societies [18-24].

The results of this study are also similar to those of other worldwide studies on the prevalence of overweight and obesity in preschool-aged children that report a growing trend in children being overweight [25-28].

These findings show that being underweight among preschool-aged children is low, but the prevalence of being overweight and obese in assessed children is evident. Based on the obtained results, we could conclude that there is a right time to prevent the malnutrition among preschool-aged children. The Kosovo Society and institutions should acknowledge the problem of malnutrition and its negative impact on the general health status of children.

The limitation of this study is that kindergartens in Kosovo have capacities to receive only a part of the preschool-aged children, so the results may not be indicative of the all preschool-aged children living in the country.
The next limitation of this study is that there are not enough background results on which to compare the present status of preschool children.

\section{Abbreviations}

BAZ: BMI-for-age z-scores; BMl: Body mass index; EU: European Union; HAZ: Length-or height-for-age z-scores; SD: Standard deviation; SPSS: Statistical Package for the Social Sciences; UNICEF: United Nations Children's Fund; WAZ: Weight-for-age z-scores; WHO: World Health Organization; WHZ: Weight-for-height z-scores)

\section{Acknowledgements}

The authors would like to acknowledge the contribution of Dr. Sanije Hoxha for her advice and support during data processing. The authors acknowledge also the children of five kindergartens, parents, teachers, cooking ladies, and directors.

\section{Funding}

This research did not receive grant from any funding agency in the public, commercial, or not-for-profit sectors.

\section{Availability of data and materials}

Please contact author for data requests.

\section{Authors' contributions}

AR wrote the first draft of this paper. He contributed also to the later drafts before submission to Journal. TMGJ was involved in revision of the paper. AP revised the first draft of this paper and contributed to later drafts. All three authors approved the present manuscript.

\section{Competing interests}

The authors declare that they have no competing interests.

\section{Consent for publication}

All authors have consented to this publication.

\section{Ethics approval and consent to participate}

Since there is no Ethic Review Committee in Kosovo, this study was approved by the Ministry of Education, Science and Technology of Kosovo. The concept and the objective of the study were explained to each parent personally, and they have signed a consent form. 


\section{Publisher's Note}

Springer Nature remains neutral with regard to jurisdictional claims in published maps and institutional affiliations.

\section{Author details}

'Department of Food Technology, Faculty of Agribusiness, University of Pejë, Rr. "UÇK-së", 30000 Pejë, Kosovo. ${ }^{2}$ Clinical Center of Kosovo, Medical Faculty, University of Prishtina, Mather Theresa, NN 10000 Prishtinë, Kosovo. ${ }^{3}$ Department of Organic Food Quality and Food Culture, Faculty of Organic Agricultural Sciences, University of Kassel, Nordbahnhofstr. 1a, 37213 Witzenhausen, Germany.

Received: 3 January 2017 Accepted: 26 May 2017

Published online: 02 June 2017

\section{References}

1. Kennedy ET. The global face of nutrition: what can governments and industry do? J Nutr. 2005;135:913-5.

2. Dennison BA, Rockwell HL, Bakeri SL. Excess fruit juice consumption by preschool-aged children is associated with short stature and obesity. Pediatr. 1997;99:15-22

3. Gonzales-Suarez C, Grimmer-Somers K, Worleyl A. Is food intake associated with pre-adolescent obesity? An observational study in Metromanila, Philippines. Asian J Clin Nutr. 2009:1:107-19.

4. Nuruddin R, Lim LK, Hadden CW, Azam I. Comparison of estimates of under-nutrition for preschool rural Pakistani children based on the WHO standard and the National Center for Health Statistics (NCHS). Public Health Nutr. 2008;12:716-22

5. Riddoch C, Edwards D, Page A, Froberg K, Anderssen SA, Wedderkop N, Brage S, Ukendt M, The European Youth Heart Study. Cardiovascular disease risk factors in children: rationale, aims, design, and validation of methods. J Phys Act Health. 2005;2:115-29.

6. Janssen I, Katzmarzyk PT, Boyce WF, Vereecken C, Mulvihil C, Roberts C, Currie C, Pickett W, Health Behavior in School-Aged Children Obesity Working Group. Comparison of overweight and obesity prevalence in school-aged youth from 34 countries and their relationships with physical activity and dietary patterns. Obes Rev. 2005:6(2):123-32. The International Association for the Study of Obesity.

7. Dehghan M, Danesh NA, Merchant AT. Childhood obesity, prevalence and prevention. Nutr J. 2005;4:24.

8. Gorstein J, Akre J. The use of anthropometry to assess nutritional status. World Health Stat Q. 1988:41:48-58.

9. Himes $J H$, Dietz WH. Guidelines for overweight in adolescent preventive services: recommendations from an expert committee. The Expert Committee on Clinical Guidelines for Overweight in Adolescent Preventive Services. Am J Clin Nutr. 1994:59:307-16.

10. Barlow SE, Dietz WH. Obesity evaluation and treatment: expert committee recommendations. The Maternal and Child Health Bureau, Health Resources and Services Administration, and the Department of Health and Human Services. Pediatr. 1998;102(3):E29.

11. Krebs NF, Himes JH, Jacobson D, Nicklas TA, Guilday P, Styne D. Assessment of child and adolescent overweight and obesity. Pediatr. 2007:120:193-228.

12. Kosovo Agency of Statistics - KAS (2010). Statistics on Education in Kosovo 2008-2009. Retrived from http://www.esk.rks-gov.net/ENG/education/ publications/docview/907-education-statistics-2009-2010?tmpl= component\&format=raw.

13. UNICEF. Action against Hunger. Nutritional Anthropometric and Infant Feeding and Weaning Survey, Pristina 1999.

14. UNICEF. Micronutrient Status Survey -Kosovo 2001; p1-2 https://www. unicef.org/kosovoprogramme/kosovo_media_pub_survival.004.04.pdf. Accessed 25 Sept 2016.

15. World Health Organisation. Physical status: The use and interpretation of anthropometry. Report of a WHO expert commitee. WHO Technical Report Series 854. Geneva: WHO; 1995

16. WHO Anthro for personal computers, version 2. Software for assessing growth and development of the world's children, Geneva 2007. www.who. int/childgrowth/software/anthro_pc_manual_v322.pdf. Accessed 25 Sept 2016.

17. WHO AnthroPlus for personal computers Manual. Software for assessing growth of the world's children and adolescents, Geneva 2009. www.who. int/growthref/tools/who_anthroplus_manual.pdf. Accessed 25 Sept 2016.
18. De Onis M, Blössner M, Borghi E. Global prevalence and trends of overweight and obesity among preschool children. Am J Clin Nutr. 2010;92: 1257-64.

19. Cattaneo A, Monasta L, Stamatakis E, Lioret S, Castetbon K, Frenken F, Manios Y, Moschonis G, Savva S, Zaborskis A, Rito Al, Nanu M, Vignerova J, Caroli M, Ludvigsson J, Koch FS, Serra-Majam L, Szponar L, Van Lenthe F, Brug J. Overweight and obesity in infants and preschool children in the European Union: a review of existing data. Obes Rev. 2010;11:389-98.

20. van Stralen MM, te Velde SJ, van Nassau F, Brug J, Grammatikaki E, Maes L, De Bourdeaudhuij I, Verbestel V, Galcheva S, lotova V, Koletzko BV, von Kries R, Bayer O, Kulaga Z, Serra-Majem L, Sánchez-Villegas A, Ribas-Barba L, Manios Y, Chinapaw MJ. Weight status of European preschool children and associations with family demographics and energy balance-related behaviors: a pooled analysis of six European studies. Obes Rev. 2012:13:29-41.

21. Poskitt EM. Countries in transition: underweight to obesity non-stop? Ann Trop Pediatr. 2009:29:1-11.

22. Jafar TH, Qadri Z, Islam M, Hatcher J, Bhutta ZA, Chaturvedi N. Rise in childhood obesity with persistently high rates of under-nutrition among urban school-aged Indo-Asian children. Arch Dis Child. 2008;93:373-8.

23. Fernald LC, Neufeld LM. Overweight with concurrent stunting in very yang children from rural Mexico: prevalence and associated factors. Eur J Clin Nutr. 2007;61:623-32.

24. Maffeis C, Consolaro A, Carvar ZP, Chini L, Banzato C, Grezzani A, Silvagni D, Salzano G, Deluca F, Tato L. Prevalence of overweight and obesity in 2-to 6year-old Italian children. Obes. 2006;14:765-9.

25. Manios Y, Costarell V, Kolotourou M, Kondakis K, Tzavara C, Moschonis G. Prevalence of obesity in preschool Greek children in relation to parental characteristics and region of residence. BMC Publ Health. 2007;25:147.

26. Gaeini A, Kashef M, Samadi A, Fallahi A. Prevalence of underweight, overweight and obesity in preschool children of Tehran, Iran. J Res Med Sci. 2010;16:821-7.

27. Juliusson PB, Eide GE, Roelants M, Waoler PE, Hauspie RB, Jerknes R. Overweight and obesity in Norwegian children: prevalence and sociodemographic risk factors. Acta paediotr. 2010;99:900-5.

28. Taheri F, Hassanzadeh TMM, Kazemi T, Nazari A, Gholamreza S. Student research committee. BMC Res Notes. 2012:5:529.

\section{Submit your next manuscript to BioMed Central and we will help you at every step:}

- We accept pre-submission inquiries

- Our selector tool helps you to find the most relevant journal

- We provide round the clock customer support

- Convenient online submission

- Thorough peer review

- Inclusion in PubMed and all major indexing services

- Maximum visibility for your research

Submit your manuscript at www.biomedcentral.com/submit
Biomed Central 